ThA2.2

9:00 am - 9:15 am

\title{
Experimental PDFA and its Application on the CATV System
}

\author{
Jingshown Wu, , Tsun-Hua Ho, and Wei-Chou Wu \\ Room 519, Department of Electrical Engineering \\ National Taiwan University, Taipei, Taiwan.
}

Shyn-Lin Tsao

Department of Electrical Engineering, Yuan Ze University

Chung-Li , Taiwan, R.O.C.

Herry Lin, Steven Chen, Holner Lin, and Michael Chin

Eastern-Broadcasting Co. L.T.D. Taipei, Taiwan

\begin{abstract}
Summary
Because many existing fiber optical communication system operate at $1.3 \mu \mathrm{m}$ band, the praseodymium-doped fluoride fiber amplifier( PDFA) is attractive for the application on these systems. A 12.8 meters praseodymium-doped fluoride fiber with doping concentration of $1000 \mathrm{ppm}$ and an Neodymium: Yttrium Lithium Fluoride ( Nd: YLF ) laser operation around $1.047 \mu \mathrm{m}$ are used to experimentally implement the PDFA. In order to have the maximum gains, the PDFA is modeled and the optimum pumping power is set accordingly. The PDFA can achieve small signal gain of $15 \mathrm{~dB}$, operating bandwidth of $27 \mathrm{~nm}$, noise figure ( NF) less than $7.5 \mathrm{~dB}$, and the amplified spontaneous emission( ASE ) noise less than $-33 \mathrm{dBm}$. Most CATV systems have the hybrid fiber/coaxial architecture. In order to have large coverage, optical splitters may be used to form a passive optical network for main distribution paths. A PDFA is an ideal candidate to amplify the signals along the transmission. The experimental setup is shown in Fig. 1. A laser source at $1300 \mathrm{~nm}$ is connected with an external modulator. The output power of the laser source is set to $12 \mathrm{dBm}$ to have the best performance. At the headend the AM-VSB channels are multiplexed and allocated from $55.25 \mathrm{MHz}$ to $83.25 \mathrm{MHz}$ and from $163.25 \mathrm{MHz}$ to $547.25 \mathrm{MHz}$ with 6 $\mathrm{MHz}$ channel spacing. Then the signals are fed into the external modulator. The optimum receiving range of optical power of the receiver is from $-7 \mathrm{dBm}$ to $0 \mathrm{dBm}$. In our system as shown in Fig. 1, the optical signal transmits through $70 \mathrm{~km}$ single mode fiber and is fed into the input of the PDFA, where the praseodymium-doped fluoride fiber( PDFF ) is 12.8 meters long and the pumping power is $650 \mathrm{~mW}$ at $1047 \mathrm{~nm}$. After the filter, an optical receiver is used to convert the optical signals to the electrical signals. Fig. 2 shows the CSO, CTB, and CNR at the receiver. The PDFA with small signal gain about
\end{abstract}


$15 \mathrm{~dB}$ and low noise characteristics $(\mathrm{NF}<7.5 \mathrm{~dB}, \mathrm{ASE}<-33 \mathrm{dBm}$ ) can successfully amplify the CATV signal to meet the system required levels. The degradation in picture qualities monitored on a TV set, with and without PDFA, are imperceptible in subjective tests. It is shown that the PDFA is applicable to the $1300 \mathrm{~nm}$ CATV system



Fig. 1 Experimental Set up with PDFA

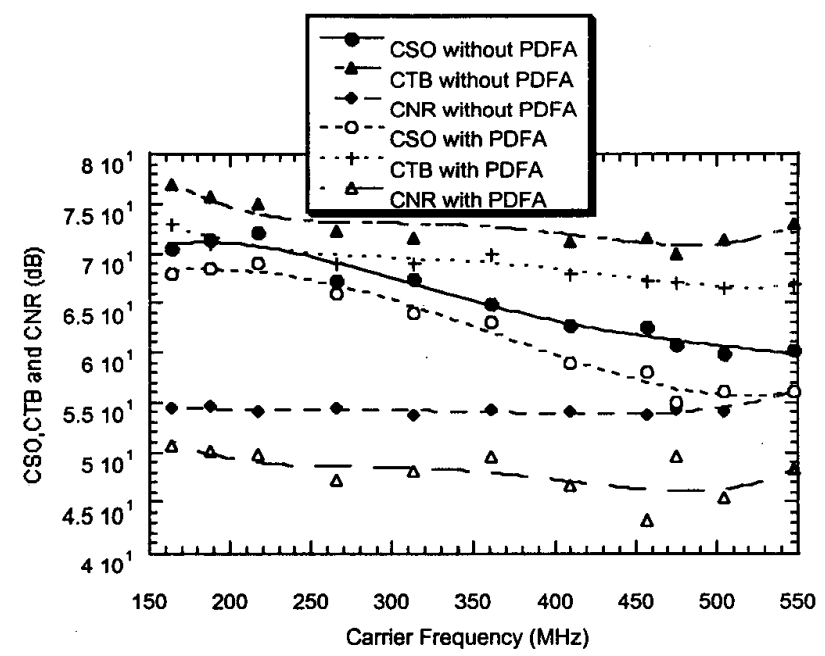

Fig. 2 experimental results without PDFA and theoretical results with PDFA 